\title{
PROTEÇÃO JURÍDICA AO CONSUMIDOR NO MERCOSUL
}

\author{
Andréa Benetti Carvalho
}

\section{RESUMO}

O Mercosul originou-se da aproximação política e comercial entre Brasil e Argentina, consolidando-se com a assinatura do Tratado de Assunção (1991) e a participação no bloco regional do Uruguai e do Paraguai. Em razão dos diferentes estágios de desenvolvimento nos Estado-parte, no que se refere à proteção jurídica do consumidor, os quatro países decidiram, conjuntamente, implementar o Comitê Técnico $\mathrm{n}^{0} 7$, a fim de atender ao estabelecido no Tratado de Assunção e harmonizar os quatro sistemas legislativos no direito consumeirista. Todos os países membros do Mercosul já dispõem de legislação específica para a defesa do consumidor. O Brasil tem o Código de Defesa do Consumidor, do ano de 1991; a Argentina regula a questão pela Lei 24.240/93; o Paraguai, pela Lei 1.334/98; no Uruguai, vigora, desde o ano de 2000, a Lei 17.250/00. O projeto de elaboração de Código comum, proposto pela Resolução 126/94 do GMC, foi rejeitado em 1997 em razão do seu caráter restritivo. Pela Decisão 10/96, aprovou-se o Protocolo de Santa Maria sobre jurisdição internacional em matéria de relações de consumo. O Comitê Técnico ${ }^{\circ}$ 7, sobre Defesa do Consumidor, ainda discute o tema.

Palavras-chaves: Defesa do Consumidor; Mercosul; jurisdição internacional.

\section{Consumer's juridical protection in Mercosul}

\section{ABSTRACT}

The Mercosul had its origins from political and commercial approach between Brasil and Argentina, having its consolidation with the signature of the Assunção Treaty (1991), and with Uruguai and Paraguai's participation in the regional bloc. Because of different levels of development in the Member States concerning consumer's juridical protection , the four countries decided to implement together the Comitê Técnico $\mathrm{n}^{\circ}$ 7, to achieve the established in the Assunção Treaty and harmonize the four legal systems in consumer's law. All the Member States of Mercosul have specified legal rules about consumer's protection. Brasil has its Código de Defesa do Consumidor, from 1991, Argentina rules the topic by its Ley 24.240/93, Paraguai by its Ley 1.334/98, and in Uruguai, since 2000 has the Ley 17.250/00. The project of elaboration of a Common Code - proposed by Resolução 126/94 GMC was rejected in 1997 because of its restrictiveness. It was approved by Decisão 10/96 the Santa Maria's Protocol about international jurisdiction in consumer's protection. The Comitê Técnico $\mathrm{n}^{0} 7$ is still discussing the subject.

Keywords: Consumer’s protection; Mercosul; International jurisdiction 


\section{Introdução}

A Constituição Federal de 1988 trouxe à sua esfera a defesa do consumidor em face da necessidade de ação terapêutica do Estado em certas situações de desequilíbrio social. O artigo $5^{\circ}$, XXXII, preceitua que “o Estado promoverá, na forma da lei, a defesa do consumidor”. O artigo $170, \mathrm{~V}^{1}$ apresenta a defesa do consumidor como princípio geral da atividade econômica, juntamente a princípios, como soberania nacional, propriedade privada e livre concorrência. Mais alusões são feitas ao tema, como o artigo $24, \mathrm{~V}^{2}$ (legislação concorrente dos entes federados no que se refere à normatização sobre produção e consumo e à responsabilidade por dano ao consumidor) e o artigo 150, $\S 5^{\circ}{ }^{3}$ (direito de informação ao consumidor a respeito de impostos incidentes sobre mercadorias e serviços). É neste contexto que surge o Código de Defesa do Consumidor em 1990, a fim de equilibrar as relações entre fornecedor e consumidor, tendo por objeto os produtos e os serviços prestados, conceitos que serão explorados no decorrer do presente trabalho.

A formação do Mercado Comum no Cone $\mathrm{Sul}^{4}$ e sua ampliação a parceiros latinoamericanos $^{5}$ representam a possibilidade de desenvolvimento sustentável na região. A livre circulação de mercadorias torna mais propenso o surgimento de controvérsias e futuros litígios na questão referente à responsabilidade sobre a produção e a distribuição de bens e serviços. Foi visando dirimir eventuais dúvidas acerca das relações de consumo no Mercosul que o Comitê Técnico $n^{0} 7$ passou a trabalhar com enfoque na harmonização legal do tema neste bloco regional.

\footnotetext{
${ }^{1}$ Art. 170. A ordem econômica, fundada na valorização do trabalho humano e na livre iniciativa, tem por fim assegurar a todos existência digna, conforme os ditames da justiça social, observados os seguintes princípios: $\mathrm{V}$ - defesa do consumidor.

${ }^{2}$ Art. 24. Compete à União, aos Estados e ao Distrito Federal legislar concorrentemente sobre: V - produção e consumo.

${ }^{3}$ Art. $150 . \S 5^{\circ}$ - A lei determinará medidas para que os consumidores sejam esclarecidos acerca dos impostos que incidam sobre mercadorias e serviços.

${ }^{4}$ Composto por Argentina, Brasil, Paraguai e Uruguai.

${ }^{5}$ Chile, Bolívia e Venezuela.
} 


\section{Direito do Consumidor}

\subsection{Histórico e evolução}

O século XIX teve como destaque econômico o surgimento do liberalismo, doutrina defensora da livre concorrência e da não-intervenção estatal na economia ${ }^{6}$. Suas conseqüências jurídicas são o positivismo e a concepção do Direito como sistema jurídico. Emerge, assim, o Direito Obrigacional, tendo como princípios básicos a autonomia da vontade das partes ${ }^{7}$ e a pacta sunt servanda ${ }^{8}$.

Dada a evolução do liberalismo, o capitalismo ganha força, as sociedades passam a concentrar os meios de produção, e surge, assim, a sociedade de consumo, que, por sua vez, prioriza a produção em série e a busca do maior mercado consumidor possível. Desta forma, o consumo (como fenômeno emergente) passa a ser influenciado pelo sistema econômico. Isto não somente porque sua origem está na cadeia produtiva da economia de mercado mas também porque "o lucro atua significativamente tanto no centro como na periferia do fenômeno; tanto na ordem material como na ordem simbólica de tudo aquilo que representa para os sujeitos”.

Todavia, mesmo sendo o consumidor figura imprescindível ao processo produtivo, sua fragilidade e vulnerabilidade perante o poderio econômico da classe produtora são patentes. Assim, a proteção jurídica ao consumidor tornou-se fato, “instando a adoção de medidas preventivas e punitivas, visando conceder ao consumidor proteção à vida, à saúde, à segurança, à liberdade de escolha e à igualdade de condições nos contratos”10 .

\footnotetext{
6 “A aplicação aos consumidores - desiguais entre si e diferentes das empresas - dos princípios fundamentais da ordem jurídica liberal (liberdade e igualdade) mostra-se freqüentemente inadequada e geralmente desprotetora de seus interesses comuns”. RICHTER, Karina. Consumidor \& Mercosul. Curitiba: Juruá, 2002. p. 22.

7 “O voluntarismo expresso através da autonomia da vontade passa a nortear a concepção de vínculo contratual, onde a propriedade traduzida no produto circulará, desde que a ordem jurídica confira tutela à vontade das partes, caracterizada como fonte criadora de direitos e obrigações contratuais, assegurando assim a produção dos efeitos almejados pelos envolvidos na relação contratual”. JACYNTHO, Patrícia Helena de Ávila; ARNOLDI, Paulo Roberto Colombo. A proteção contratual ao consumidor no Mercosul. Campinas: Interlex, 2001. p. 16.

${ }^{8}$ Por este princípio, o contrato consentido livremente pelas partes passa a ter o caráter da imperatividade, ou seja, ter força de lei entre os contratantes.

${ }^{9}$ RICHTER, Karina. Op. cit. p. 23.

${ }^{10}$ JACYNTHO, Patrícia Helena de Ávila et alli. Op. cit. p. 17.
} 
A partir das primeiras décadas do século XX, o cenário mundial muda, e os contratos de consumo não se realizam mais entre sujeitos livres e conscientes de suas conseqüências, mas entre grupos econômicos (representados por empresas com grande aporte financeiro) e sujeitos isolados, "carentes de conhecimentos e informações adequadas em relação ao acordo" ${ }^{11}$ ao qual se submetem e com o qual anuem. Tal desequilíbrio contratual faz-se presente pelo poderio econômico e financeiro desses grupos econômicos, que se utilizam das normas legais genéricas ao seu favor e pelo contrato abusivo que coloca o consumidor fora do mercado.

\footnotetext{
“Ao mesmo tempo, o desequilíbrio econômico, em detrimento do consumidor, gerava tensões estruturais no seio do desenvolvimento das políticas econômicas estatais. Portanto, o tratamento jurídico desfavorável do fenômeno do consumo tornou-se um problema para os governos". 12
}

Como forma de atuação consciente a fim de regular tal disparidade, o Estado passa a adotar políticas de consumo por meio de programas governamentais.

Com o grande desenvolvimento econômico global após a II Guerra Mundial, a produção e o comércio (nacional e internacional) massificaram-se, evidenciando a necessidade da tutela legal estatal específica dos consumidores.

\begin{abstract}
"Especialmente nesse período viu-se desenvolver de maneira bastante generalizada entre as economias capitalistas mundiais a 'sociedade de consumo' (mass consumption society) nos padrões pioneiramente estabelecidos nos Estados Unidos, tendo sido rapidamente acompanhada pelas demais sociedades capitalistas avançadas, e é nesse ambiente que se desenvolverá o direito do consumidor”. ${ }^{13}$
\end{abstract}

\footnotetext{
${ }^{11}$ RICHTER, Karina. Op. cit. p. 25.

${ }^{12}$ RICHTER, Karina. Op. cit. p. 25.

${ }^{13}$ PERIN JR, Ecio. A globalização e o Direito do Consumidor - aspectos relevantes sobre a harmonização legislativa dentro dos mercados regionais. Barueri: Manole, 2003. p. 9.
} 


\subsubsection{Proteção ao consumidor nos Estados Unidos da América}

No ano de 1899, surge, nos Estados Unidos, a National Consumer League ${ }^{14}$, a fim de proteger o consumidor estadunidense do capitalismo monopolista e oligopólico que ganhava força naquele país. Sete anos depois, em 1906, são aprovados o Pure Food and Drug Act e o Meat Inspection Act $^{15}$, resultando na criação, em 1914, da Federal Trade Comission $^{16}$. Mara Suely Oliveira e Silva Maran explica, em seus estudos ${ }^{17}$, que, além da FTC, há outras quatro agências governamentais especializadas que podem ser citadas:

“a) Consumer's Education Office, com a incumbência de promover e administrar programas educacionais voltados para a formação e treinamento de pessoal especializado em educação e orientação do consumidor;

b) Food and Drug Administration, encarregada da fiscalização de produtos comestíveis, farmacêuticos, cosméticos e drogas;

c) Consumer Product Safety Comission, que cuida das normas e padrões de segurança dos produtos e fiscaliza sua aplicação;

d) Small Claim Courts, que é semelhante aos nossos Juizados de Pequenas Causas, que atendem as reclamações de consumidores desobstruindo a Justiça Comum”.

Na década de 30, novo destaque teve o movimento consumeirista estadunidense, desta vez, com os protestos populares por causa do aumento de preços em resposta à Grande Depressão de 1929. Contudo, somente na década de 60, a proteção jurídica ao consumidor ganhou efetividade nos Estados Unidos. Já em campanha presidencial, John Kennedy assumiu a causa. Em 1962, encaminhou ao Congresso americano a Special message to the Congress on protecting the consumer interest ${ }^{18}$, e, no ano seguinte,

\footnotetext{
${ }^{14}$ Hoje a Consumers League denomina-se Consumers Union, e atua na conscientização dos consumidores, na promoção de procedimentos e processos judiciais.

${ }^{15}$ Estas duas leis foram o resultado da pesquisa e a constatação feita por Upton Sinclair sobre as condições de fabricação dos embutidos de carne e dos matadouros de Chicago, assim como a precária condição de higiene que afetava os trabalhadores e o produto final, conseqüentemente atingindo o consumidor.

${ }^{16} \mathrm{O}$ objetivo da FTC é aplicar as leis antitruste e proteger os interesses do consumidor. Dotada de amplos poderes investigatórios e acesso a documentos e livros contábeis das empresas, tem atuação destacada em casos de fraude e publicidade enganosa.

${ }^{17}$ MARAN, Mara Suely Oliveira e Silva. Publicidade \& proteção ao consumidor no âmbito do Mercosul. Curitiba: Juruá, 2003. p. 57.

${ }^{18}$ Uma mensagem especial ao Congresso referente à proteção ao consumidor.
} 
implantava o Consumer Advisory Council First Report ${ }^{19}$. O Direito do Consumidor aparece nos Estados Unidos com perspectiva individualista e reparatória, protegendo-se, inicialmente, o indivíduo consumidor para, depois, passar à proteção coletiva.

“(...) em ambos os sistemas - common law e civil law - o Direito do Consumidor, que havia nascido como corpo legal eminentemente repressivo (penal e administrativo), foi aos poucos se transformando, em face de certas características do mercado (...). E hoje o Direito do Consumidor é fundamentalmente preventivo", ${ }^{20}$

\subsubsection{Proteção ao consumidor na Europa}

A partir de 1910, o movimento consumeirista europeu inicia-se com a instituição de organismos administrativos em favor dos consumidores na França, na Inglaterra, na Suécia e na Holanda ${ }^{21}$. Em 1957, surge, na Inglaterra, a Consumers Association. Um ano mais tarde, instaura-se a comissão especial no Parlamento inglês, o Committee on Consumer Protection. Como resultado do trabalho, promulgou-se, em 1961, o Consumer Protection Act, e publicou-se, em 1963, o Molony Report (Final Report of the Committee on Consumer Protection) $)^{22}$.

No início da década de 70, é criado, na Suécia, o ombdusman, órgão público especializado em atendimento de reclamações de consumidores com competência para dar o prosseguimento judicial cabível caso a mediação não resulte em satisfação a ambas as partes (reclamante e reclamado). O modelo é seguido pelos demais países escandinavos ${ }^{23}$.

A pioneira na normatização contra cláusulas abusivas em contratos de adesão é a Alemanha, com a Lei sobre Regulamentação das Condições Gerais de Contratação, de 1976. Enfim, na Comunidade Européia, o movimento consumeirista consolidou-se, tendo

\footnotetext{
${ }^{19}$ Primeiro programa de política pública cujo objetivo é tutelar o consumidor de que se tem notícia. Reconhecia quatro direitos básicos ao consumidor: segurança, informação, eleição e direito de ser ouvido.

${ }^{20}$ GRINOVER, Ada Pellegrini. O Código de Defesa do Consumidor no sistema socioeconômico brasileiro. In: Revista da Faculdade de Direito de São Paulo. São Paulo: USP, n. 91, p. 277-287, jan./dez. 1996. p. 278.

${ }^{21}$ PERIN JR, Ecio. Op. cit. p. 10-11.

22 "Basicamente, o Molony Report, ao longo de seus vinte e dois capítulos, estabelece uma análise detalhada das diversas questões que afetam as relações de consumo, assim como também expõe a necessidade da criação de novos referenciais jurídicos orientados para a defesa dos consumidores”. RICHTER, Karina. Op. cit. p. 32.
}

${ }^{23}$ Noruega (1972), Dinamarca (1974) e Finlândia (1978). 
evoluído o Direito do Consumidor não só na União Européia como também em seus Estados-Membros. Por toda a Europa, a evolução da proteção jurídica ao consumidor surgiu do esforço em tutelar o coletivo, "sendo secundária a preocupação de reparar os danos sofridos pelos consumidores”24, distintamente do que ocorreu nos Estados Unidos.

\subsubsection{Proteção internacional ao consumidor}

Em âmbito mundial, pode-se indicar que o movimento consumeirista inicia-se em 1960, com a International Organization of Consumers Unions, hoje, conhecida por Consumers International. Esta organização internacional representada por mais de 200 associações, distribuídas em mais de 80 países, exerce influência junto a governos e organismos internacionais na defesa aos direitos dos consumidores.

A Organização das Nações Unidas inovou na defesa do consumidor ao recomendar que este deve ser convenientemente educado quanto aos seus direitos pela Resolução 2.542, que declara os Direitos Fundamentais e Universais do Consumidor. Mas, o avanço significativo na matéria, no âmbito da ONU, ocorreu em 1985, por meio da Resolução 39/248, com o estabelecimento de objetivos, princípios e normas a serem desenvolvidos pelos governos nacionais.

\footnotetext{
"Este conjunto de afirmações representa claramente e, pela primeira vez, no âmbito mundial, o alto grau de reconhecimento e aceitação atuais dos conceitos dos direitos básicos do consumidor. O Anexo 3 da Resolução detalha os princípios gerais que os governos devem considerar, voluntariamente, como padrões mínimos na formação das políticas legislativas nacionais. Declara os direitos dos consumidores como universais e indisponíveis”. ${ }^{25}$
}

${ }^{24}$ GRINOVER, Ada Pellegrini. O Código de Defesa do Consumidor no sistema socioeconômico brasileiro. Op. cit. p. 278.

${ }^{25}$ RICHTER, Karina. Op. cit. p. 40. 
Com base nesta Resolução, surgiu, em 1990, o Código de Proteção e Defesa do Consumidor brasileiro.

\section{Direito do Consumidor no Mercosul}

\subsection{Comitê Técnico n 7}

A Comissão de Comércio do Mercosul tem a competência de velar pela aplicação dos instrumentos de política comercial comum em que os Estados-Membros acordaram, bem como dar seguimento e revisão dos temas e das matérias relacionados com as políticas comerciais comuns, com o comércio dentro do bloco e com terceiros Estados. Dada a sua competência, a CCM divide-se em comitês técnicos criados para o melhor cumprimento das funções, por meio de Diretrizes, de acordo com as necessidades da CCM. Tais comitês não têm faculdades decisórias e devem reportar suas atividades e recomendações à CCM, por meio da presidência pro tempore.

Atualmente, são sete os comitês técnicos do Mercosul:

a) Comitê Técnico n ${ }^{0} 1$ - Tarifas, Nomenclatura e Classificação de Mercadorias;

b) Comitê Técnico $n^{0} 2$ - Assuntos Aduaneiros;

c) Comitê Técnico n ${ }^{0} 3$ - Normas e Disciplinas Comerciais;

d) Comitê Técnico n ${ }^{0} 4$ - Políticas Públicas que distorcem a Competitividade;

e) Comitê Técnico $n^{0} 5$ - Defesa da Concorrência;

f) Comitê Técnico $n^{0} 6$ - Defesa Comercial e Salvaguardas;

g) Comitê Técnico $n^{0} 7$ - Defesa do Consumidor.

A fim de harmonizar as legislações nacionais dos Estados-Membros do Mercosul e estabelecer tratados com standards mínimos de legislação consumeirista, o CT-7 trabalha no sentido de dar maior proteção ao consumidor no âmbito do bloco. Criado em 1995, pela Diretriz CCM 1/1995, o CT-7 é representado no Brasil pelo Departamento de Proteção e Defesa do Consumidor do Ministério da Justiça. 


\subsection{Harmonização das normas consumeiristas no Mercosul}

Tendo em vista suas prerrogativas, o Comitê Técnico $\mathrm{n}^{0} 7$ passou a trabalhar focalizando a melhor forma de regulamentação e harmonização dos interesses consumeiristas no âmbito do Mercosul.

\subsubsection{Resoluções GMC}

O Grupo Mercado Comum editou, em 1994, a primeira Norma-Mercosul Geral sobre direito do consumidor: a Resolução 126/94. Seu considerando já menciona a harmonização legislativa mercosulina, tendo, como agente econômico mais vulnerável, o consumidor. Todavia, a aplicação da Resolução 126/94 está condicionada à aprovação do Regulamento Comum sobre Defesa do Consumidor no Mercosul, como explica o artigo $2^{\circ}$ :

\footnotetext{
“Até que seja aprovado um regulamento comum para a defesa do consumidor no Mercosul, cada Estado Parte aplicará sua legislação de defesa do consumidor e regulamentos técnicos pertinentes aos produtos e serviços comercializados em seu território. Em nenhum caso, essas legislações e regulamentos técnicos poderão resultar na imposição de exigências aos produtos e serviços oriundos dos demais Estado-parte superiores àquelas vigentes para os produtos e serviços nacionais ou oriundos de terceiros países”.
}

Ante o colocado pela Resolução 126/94, destaque-se o igual tratamento a produtos ou serviços estrangeiros no Mercosul, assim como a aplicabilidade das normas do mercado nacional de comercialização.

Atendendo ao conteúdo que previa nova reunião da Comissão de Direito do Consumidor do Sub-Grupo de Trabalho 10 no ano seguinte, a fim de elaborar o Protocolo Internacional de Defesa ao Consumidor, a Resolução colocou, em anexo, um Plano de Trabalho, que continha os seguintes itens como temas a serem desenvolvidos: princípios que regem a defesa do consumidor; oferta de serviços; garantia de serviços; práticas abusivas (serviços); publicidade enganosa e abusiva; proteção contratual (contratos, 
cláusulas abusivas e contratos de adesão); responsabilidade objetiva; decadência e prescrição; banco de dados.

No ano de 1996, o GMC aprovou cinco capítulos do que viria a ser o Regulamento Comum sobre Defesa do Consumidor no Mercosul, sob a forma de Resoluções. A Resolução 123/96 traz os conceitos básicos da relação de consumo, como consumidor, fornecedor, produtos e serviços ${ }^{26}$. A Resolução 124/96 elenca, em seu anexo, os direitos básicos dos consumidores, os quais vêm a ser reiterados na Declaração Presidencial de Direitos Fundamentais dos Consumidores do Mercosul ${ }^{27}$.

\footnotetext{
${ }^{26}$ Anexo: Conceitos:

I - Consumidor: é toda pessoa física ou jurídica que adquire ou utiliza produtos ou serviços como destinatário final em uma relação de consumo ou em função dela. Equipara-se a consumidor a coletividade de pessoas, determináveis ou não, expostas às relações de consumo. Não se considera consumidor ou usuário aquele que, sem constituir-se destinatário final, adquire, armazena, utiliza ou consome produtos ou serviços com o fim de integrá-los em processos de produção, transformação, comercialização ou prestação a terceiros.

II - Fornecedor: é toda pessoa física ou jurídica, pública ou privada, nacional ou estrangeira, assim como os entes despersonalizados nos Estado-parte cuja existência esteja contemplada em seu ordenamento jurídico, que desenvolvam de maneira profissional atividades de produção, montagem, criação seguida de execução, construção, transformação, importação, distribuição e comercialização de produtos e/ou serviços em uma relação de consumo.

III - Relação de consumo: é o vínculo que se estabelece entre o fornecedor que, a título oneroso, fornece um produto ou presta um serviço e quem o adquire ou utiliza como destinatário final. Equipara-se ao fornecimento de produtos e à prestação de serviços a título gratuito quando se realizam em função de eventual relação de consumo.

IV - Produto: é qualquer bem móvel ou imóvel, material ou imaterial.

V - Serviços: As precisões sobre esse conceito continuarão sendo objeto de harmonização pelos Estado-parte.

${ }^{27}$ Cf. o item 2.2.4.
} 
A terceira Resolução, aprovada em Direito do Consumidor pelo GMC no ano de 1996, foi a 125/96, que defende a proteção à saúde e à segurança do consumidor ${ }^{28}$. A quarta Resolução foi a 126/96, que estabeleceu standards mínimos de proteção ao consumidor no que se refere à publicidade ${ }^{29}$.

${ }^{28}$ Anexo: Proteção à saúde e segurança do consumidor: I - Os produtos e serviços somente poderão ser colocados pelos fornecedores no mercado de consumo quando não apresentem riscos à saúde ou segurança dos consumidores, exceto os considerados normais e previsíveis por sua natureza ou utilização. Os fornecedores não poderão colocar no mercado de consumo produtos ou serviços que apresentem, para a saúde ou segurança do consumidor, alto grau de nocividade e periculosidade, considerado pelas autoridades competentes no âmbito do Mercosul, qualquer que seja seu uso ou utilização.

II - Os fornecedores de bens e serviços devem proporcionar aos consumidores ou usuários, de forma certa e objetiva, informação veraz, eficaz e suficiente sobre suas características essenciais, de acordo com a sua natureza. Em se tratando de produtos industriais, o fabricante deverá prestar as informações a que se refere este artigo.

III - Todos os bens e serviços cuja utilização possa supor um risco, que seja considerado normal e previsível pela sua natureza e utilização, à saúde ou à integridade física dos consumidores ou usuários devem ser comercializados observando-se as normas estabelecidas ou razoáveis para garantir a segurança dos mesmos.

IV - Os fornecedores de produtos ou serviços perigosos ou nocivos à saúde ou segurança deverão informar, de forma ostensiva e adequada, sobre sua periculosidade ou nocividade, sem prejuízo da adoção de outras medidas que se possam tomar em cada caso. Os fornecedores de produtos ou serviços que, posteriormente à introdução no mercado de consumo, tenham conhecimento de sua periculosidade deverão comunicar imediatamente tal circunstância às autoridades competentes e aos consumidores mediante anúncios publicitários.

V - Quando um dos Estado-parte tenha conhecimento da periculosidade ou nocividade de produtos ou serviços para a saúde ou segurança dos consumidores, deverá informar imediatamente os demais Estado-parte sobre tal circunstância.

${ }^{29}$ Anexo: Publicidade:

I) Toda publicidade deve ser transmitida e divulgada de tal forma que o consumidor imediatamente a identifique como tal.

II) Fica proibida qualquer publicidade enganosa. Entender-se-á por publicidade enganosa qualquer modalidade de informação, difusão ou comunicação de caráter publicitário que seja inteira ou parcialmente falsa, ou que de qualquer outro modo, inclusive por omissão de seus dados essenciais, seja capaz de induzir a erro o consumidor, quando do fornecimento de informações a respeito da natureza, características, qualidade, quantidade, propriedades, origem, preço, condições de comercialização, e quaisquer outros dados essenciais sobre produtos e serviços que sejam necessários para decidir uma relação de consumo.

III) A publicidade comparativa será permitida sempre que sejam respeitados os seguintes princípios e limites:

a) que não seja enganosa;

b) seu principal objetivo seja o esclarecimento da informação ao consumidor;

c) tenha por princípio básico a objetividade na comparação e não dados subjetivos, de caráter psicológico ou emocional;

d) a comparação seja passível de comprovação;

e) não se configure como concorrência desleal, desprestigiando a imagem de produtos, serviços ou marcas de outras empresas;

f) não estabeleça confusão entre os produtos, serviços ou marcas de outras empresas.

IV) Não será permitida a publicidade comparativa quando seu objetivo seja a declaração geral e indiscriminada da superioridade de um produto ou serviço sobre outro.

V) O ônus da prova da veracidade e correção da informação ou comunicação publicitária recairá sobre o anunciante.

VI) Cada Estado Parte, internamente, poderá exigir que o fornecedor de produtos e serviços mantenha em seu poder, para a informação dos legítimos interessados, os dados fáticos, técnicos e científicos que dão sustentação à mensagem publicitária. 
Finalmente, a última Resolução daquele ano, a 127/96, dispõe sobre a garantia contratual na relação de consumo ${ }^{30}$ e foi substituída pela 42/98, cujo conteúdo permaneceu inalterado. Note-se que todas as Resoluções adotam fórmula minimalista, afirmando, em todos os considerandos, que, em sendo a harmonização parcial, na medida em que se avançar no processo, os conceitos poderão ser ampliados e/ ou complementados.

\subsubsection{Protocolo de Santa Maria}

O Protocolo de Santa Maria sobre Jurisdição Internacional em Matéria de Relações de Consumo é o mais avançado tratado acordado entre os Estado-parte do Mercosul, no que se refere à proteção jurídica ao consumidor, no âmbito deste bloco regional. Datado de 22 de novembro de 1996, ainda não entrou em vigor em nenhum dos Estados-Membros do bloco porque necessita de aprovação prévia do Regulamento Comum Mercosul de Defesa do Consumidor, bem como sua internalização nos Estado-parte ${ }^{31}$.

"A razão deste conectar entre estas duas normas do Mercosul nos escapa, mas significa na prática que o belo protocolo ficou em um limbo jurídico nunca entrando 'em vigor' (...)”. ${ }^{32}$

\footnotetext{
${ }^{30}$ Anexo: Garantia contratual:

I) Quando o fornecedor de produtos e serviços oferecer garantia, deverá fazê-lo por meio de termo escrito, padronizado para produtos idênticos, em idioma do país de consumo, espanhol ou português e sem prejuízo de que, além destes, se possam utilizar outros idiomas, devendo ser de fácil compreensão, com letra clara e legível, e informar ao consumidor sobre o alcance dos aspectos mais significativos da mesma.

II) O termo de garantia deverá conter, no mínimo, as seguintes informações:

a) identificação de quem oferece a garantia;

b) identificação do fabricante ou importador do produto ou prestador do serviço;

c) identificação precisa do produto ou serviço, com suas especificações técnicas básicas;

d) condições de validade da garantia, seu prazo e abrangências, especificando as partes do produto ou serviço a serem cobertas pela garantia;

e) domicílio e telefone daqueles que estão obrigados contratualmente a prestar a garantia;

f) condições de reparação do produto ou serviço, com especificação do lugar onde se efetivará a garantia;

g) custos a cargo do consumidor, se houver ;

h) lugar e data do fornecimento do produto ou serviço ao consumidor.

III) O termo de garantia deverá ser preenchido pelo fornecedor e entregue juntamente com o produto ou no momento do término do serviço.

${ }^{31}$ Artigo $18^{\circ}$. A tramitação da aprovação do presente Protocolo no âmbito de cada um dos Estado-parte, com as adequações que forem necessárias somente terá início após a aprovação do "Regulamento Comum MERCOSUL de Defesa do Consumidor" em sua totalidade, inclusive eventuais anexos, pelo Conselho do Mercado Comum.

${ }^{32}$ MARQUES, Cláudia Lima. Direitos do Consumidor no Mercosul: algumas sugestões frente ao impasse. In: Revista de Direito do Consumidor. São Paulo: Revista dos Tribunais, n. 31, p. 16-44, jul./set.1999. p. 34
} 
O PSM é assinado levando-se em consideração o compromisso pré-estabelecido no Tratado de Assunção em harmonizar as legislações dos Estado-parte nas áreas pertinentes, e ante a necessidade de acordo no que se refere a soluções jurídicas comuns, a fim de fortalecer o processo de integração. O preâmbulo do tratado assim dispõe:

"DESTACANDO a necessidade de proporcionar ao setor privado dos Estado-parte um marco de segurança jurídica que garanta soluções justas e a harmonia das decisões jurisdicionais vinculadas às relações de consumo;

CONVENCIDOS da necessidade de se dar proteção ao consumidor e da importância de se adotarem regras comuns sobre jurisdição internacional em matéria de relações de consumo derivadas de contratos entre fornecedores de bens ou prestadores de serviço e consumidores ou usuários;

CONSCIENTES de que, em matéria de negócios internacionais, a contratação é a expressão jurídica do comércio, sendo especialmente relevante no processo de integração”.

O âmbito de abrangência material do referido Protocolo, conforme o artigo $1^{\circ}$, diz respeito às relações de consumo que tratarem de venda a prazo de bens móveis corpóreos; empréstimo a prazo ou de outra operação de crédito ligada ao financiamento na venda de bens; qualquer outro contrato que tenha por objeto a prestação de um serviço ou fornecimento de bem móvel corpóreo. Vale citar que se excluem as relações de consumo decorrentes de contratos de transporte.

Deste Protocolo resulta em que as cláusulas de eleição de foro foram legisladas pelo Mercosul, afastando a autonomia da vontade das partes, sempre que os contratos de consumo e consumidor e fornecedor tenham domicílio em distintos Estado-parte do Mercosul. Desta forma, o consumidor passa a ter foro privilegiado e à sua escolha ${ }^{33}$, bem como lhe é facilitado o reconhecimento de sentenças e juízo à distância. Ademais, o PSM apresenta, em seu anexo, a definição do que vem a ser a relação de consumo, assim como demais conceitos necessários ao seu entendimento, tais quais, consumidor, fornecedor, produto e serviços.

\footnotetext{
${ }^{33}$ Artigo $4^{\circ}$. Regra geral. 1. Terão jurisdição internacional nas demandas ajuizadas pelo consumidor, que versem sobre relações de consumo, os juizes ou tribunais do Estado em cujo território esteja domiciliado o consumidor. 2. O fornecedor de bens ou serviços poderá demandar contra o consumidor perante juiz ou tribunal do domicílio deste.
} 


\section{“a) CONSUMIDOR}

É toda a pessoa física ou jurídica que adquire ou utiliza produtos ou serviços como destinatário final em uma relação de consumo ou em função dela. Equipara-se a consumidor a coletividade de pessoas, determináveis ou não, expostas às relações de consumo. Não se considera consumidor ou usuário aquele que, sem constituir-se em destinatário final, adquire, armazena, utiliza ou consome produtos ou serviços com o fim de integrá-los em processos de produção, transformação, comercialização ou prestação de serviços.

b) FORNECEDOR

É toda a pessoa física ou jurídica, pública ou privada, nacional ou estrangeira, assim como os entes despersonalizados nos Estado-parte cuja existência esteja contemplada em seu ordenamento jurídico, que desenvolvam de maneira profissional atividades de produção, montagem, criação seguida de execução, construção, transformação, importação, distribuição e comercialização de produtos e/ou serviços em uma relação de consumo.

c) RELAÇÃO DE CONSUMO

É o vínculo que se estabelece entre o fornecedor que, a título oneroso, fornece um produto ou presta um serviço, e quem o adquire ou utiliza como destinatário final. Equipara-se a esta o fornecimento de produtos e a prestação de serviços a título gratuito, quando se realizem em função de uma eventual relação de consumo.

d) PRODUTO

É qualquer bem móvel ou imóvel, material ou imaterial.

e) SERVIÇOS

Enquanto o Comitê Técnico $n^{\circ} 7$ (Defesa do Consumidor) não tenha acordado uma definição para serviços, será adotada, para os efeitos do Protocolo, a interpretação jurídica do foro atuante.”

Apesar de algumas críticas a este Protocolo, como, por exemplo, a aplicação subsidiária do Protocolo de Buenos Aires sobre Jurisdição Internacional em Matéria Contratual, de 5 de agosto de 1994, sua elaboração significou avanço na matéria consumeirista no Mercosul.

\subsubsection{Regulamento Comum sobre Defesa do Consumidor no Mercosul}

Em 1996, o tema da defesa do consumidor no Mercosul passou a ser visto com desconfiança e como algo polêmico. A Comissão de Comércio do Mercosul passou a preparar corpo único de normas que regularia o tema nos Estado-parte do bloco. O mandato para harmonização legislativa constante do Tratado de Assunção passou a ser visto mediante a necessidade de criar pautas mínimas de proteção ao consumidor na região, a 
iniciar pela elaboração de um Regulamento Comum sobre Defesa do Consumidor no Mercosul, que seria mais um Protocolo Internacional do bloco.

A Resolução GMC 126/94 mencionava, no primeiro artigo, a tarefa de elaborar um Regulamento Comum de proteção ao consumidor. Este Protocolo chegou a ser elaborado e editado em partes como Resoluções do GMC, como analisado no item 2.2.1.

No ano de 1997, o Protocolo de Defesa do Consumidor no Mercosul foi aprovado pelo Ministério da Justiça brasileiro, tendo sido, posteriormente, recusado pela delegação brasileira na CCM, no mesmo ano. Foi considerado pela CCM mero texto de trabalho, sendo sua apreciação pelo Presidente da República desnecessária. A recusa da delegação brasileira ocorreu por motivo justificável do ponto de vista brasileiro: o Protocolo, quando ratificado e internalizado pelo Brasil, reduziria as garantias e as proteções conferidas ao consumidor pelo Código de Defesa do Consumidor. E foi mais adiante:

"El documento no atiende a la orientación establecida en el MERCOSUR, según la cual, en el proceso de armonización, se tendrá como referencia la legislación más exigente y los standards internacionales. Por este motivo la delegación de Brasil no aprobó dicho documento en la CCM. La delegación de Brasil ya había manifestado, en el ámbito del CT $\mathrm{N}^{\circ} 7$, su disconformidad con la propuesta de conferir al documento el status de protocolo, habiendo subrayado que el mismo carecía de consistencia”. ${ }^{34}$

As negociações acerca do projeto não foram retomadas. Todavia, os esforços de harmonização recomeçaram no ano seguinte, em 1998, de forma tópica e limitada.

\subsubsection{Declaração Presidencial de Direitos Fundamentais dos Consumidores do Mercosul}

Foi firmada em 15 de dezembro de 2000, no âmbito do Mercosul, a Declaração Presidencial de Direitos dos Consumidores no bloco. Apesar do avanço na matéria, tal declaração não constitui mais que uma carta de boas intenções.

Esta Declaração tem seu início levando-se em consideração o desenvolvimento econômico equilibrado no Mercosul; as relações transparentes, harmônicas e leais no

\footnotetext{
${ }^{34}$ MERCOSUR/CCM/XXV/Acta 07/97.
} 
mercado de consumo; o desenvolvimento econômico com justiça social; a ampliação da oferta e da qualidade dos produtos e dos serviços disponíveis; o direito de acesso e escolha dos consumidores; a melhor inserção dos setores produtivos do Mercosul no mercado internacional; o equilíbrio da relação de consumo com base na boa-fé; a harmonização das legislações nacionais dos Estado-parte no bloco em Direito do Consumidor. Estabelece, mais adiante, alguns direitos fundamentais de todo e qualquer consumidor: proteção à vida, à saúde e à segurança do consumidor e do meio ambiente; equilíbrio nas relações de consumo, dignidade, lealdade e boa-fé; fornecimento de produtos e serviços em condições adequadas e seguras; liberdade de escolha; prevenção e reparação de danos ao consumidor e sanção aos responsáveis; educação para o consumo; informação; proteção contra publicidade abusiva e enganosa; proteção contra práticas abusivas, cláusulas abusivas ou métodos coercitivos desleais; facilitação de acesso aos meios alternativos de solução de controvérsias.

\subsubsection{Acordo Interinstitucional de Entendimento entre os Órgãos de Defesa do Consumidor dos Estado-parte do Mercosul para a Defesa do Consumidor Visitante}

No dia 3 de junho de 2004, foi assinado pelos Estados-Membros do Mercosul o Acordo Interinstitucional de Entendimento entre os Órgãos de Defesa do Consumidor dos Estado-parte do Mercosul para a Defesa do Consumidor Visitante, que permite a brasileiros, argentinos, paraguaios e uruguaios serem atendidos por órgãos de defesa do consumidor em qualquer um dos países do Mercosul quando estiverem em trânsito. O acordo faz parte dos trabalhos do Comitê Técnico do CT-7 e tem como objetivo garantir a efetiva proteção dos consumidores da região que se encontrem transitoriamente em outro país do bloco, beneficiando, principalmente, os turistas.

Pelo texto assinado, os países comprometem-se a assessorar e informar os consumidores a respeito de seus direitos, colocar à disposição mecanismos ágeis para a solução de conflitos relativos a consumo (seguindo as normas e os procedimentos do país anfitrião), estabelecer mecanismos de informação recíproca sobre o curso das reclamações e analisar conjuntamente os resultados do acordo ${ }^{35}$. Para assegurar o cumprimento do

\footnotetext{
${ }^{35}$ Artigo $3^{\circ}$. As partes acordam as seguintes ações:
} 
tratado, as partes comprometeram-se a promovê-lo entre os órgãos locais de defesa do consumidor de seus respectivos países, nos Estado-parte em que aqueles existam, e a manter informadas as demais partes a respeito ${ }^{36}$.

\section{Considerações Finais}

O homem vive numa sociedade de consumo, cujas características são a crescente quantidade de produtos e serviços consumidos e as dificuldades de acesso à justiça. "São esses aspectos que marcaram o nascimento e desenvolvimento do direito do consumidor, como disciplina jurídica autônoma”37. A Konsumgesellschaft ${ }^{38}$ não nos trouxe benefícios apenas: a posição do consumidor na relação de consumo antes paritária (na qual fornecedor e consumidor tinham relacionamento mais próximo, sendo o poder de barganha facilitado) passa a ser regida pelo ditame de regras do fornecedor. Tal vulnerabilidade do consumidor não pode, e não consegue, ser suprida pelo mercado (porque não é a isto que serve).

Neste contexto, faz-se necessária a intervenção estatal, normatizando as relações de consumo e "dirimindo conflitos decorrentes dos esforços de formulação e de implementação"39. No âmbito do Mercosul, é prioritária a regulamentação protetiva ao consumidor, dada a vocação internacional do Direito do Consumidor.

a) assessorar e informar aos consumidores a que se refere este Acordo a respeito de seus direitos, em particular, os relacionados com os produtos e serviços que adquiram ou contratem durante sua estada em Estado-Parte distinto daquele de seu domicilio.

b) conforme o desenvolvimento alcançado em cada localidade de seus respectivos países, pôr à disposição desses consumidores mecanismos ágeis e eficazes, para possibilitar a solução dos conflitos que possam ocorrer durante sua estadia, tendentes a um rápido tratamento do problema apresentado pelo consumidor visitante e de acordo com as normas e procedimentos do país anfitrião.

c) as partes procurarão mecanismos de informação recíproca e/ou aos consumidores visitantes acerca do curso das denúncias ou reclamações formuladas nos termos do presente Acordo.

d) as partes analisarão em conjunto os resultados da operação implementada com o objetivo de determinar se é necessário introduzir novas normas ou modalidades operativas para assegurar a adequada proteção dos consumidores a que se refere este Acordo.

${ }^{36}$ Artigo $4^{\circ}$ do Acordo Interinstitucional de Entendimento entre os Órgãos de Defesa do Consumidor dos Estado-parte do Mercosul para a Defesa do Consumidor Visitante.

${ }^{37}$ GRINOVER, Ada Pellegrinni. Op. cit. Página 6.

${ }^{38}$ Sociedade de consumo.

${ }^{39}$ GRINOVER, Ada Pellegrinni. Op. cit. Página 7. 
“Mesmo em uma União Aduaneira imperfeita como o Mercosul, o consumidor não deve ser prejudicado, seja sob o plano da segurança, da qualidade, da garantia ou do acesso à justiça, somente porque adquire produto ou utiliza serviços proveniente de um outro país ou fornecido por empresa com sede no exterior". ${ }^{40}$

Assim, a proteção ao consumidor em nível regional entende-se como primordial, sendo um dos objetivos naturais da integração econômica ${ }^{41}$. As regras de Direito do Consumidor interessam à competitividade do mercado interno e, conseqüentemente, refletem em regras de competitividade internacional, contribuindo para a criação do mercado interno com concorrência leal.

\section{Referências}

A HISTÓRIA da defesa do consumidor no Brasil: 1975-2000. Porto Alegre: Nova Editora, 2001.

ACCIOLY, Elizabeth. Mercosul e União Européia: estrutura jurídico-institucional. 2. ed. Curitiba: Juruá, 1999.

Sistema de solução de controvérsias em blocos econômicos: contributo para o sistema permanente de solução de controvérsias do Mercosul. Coimbra: Almedina, 2004.

\section{ALLEMAR, Aguinaldo. Legislação de consumo no âmbito da ONU e da União}

Européia. Curitiba: Juruá, 2003.

ALVIM, Thereza. Et al. Código de defesa do consumidor comentado. 2. ed. São Paulo: Revista dos Tribunais, 1995.

\footnotetext{
${ }^{40}$ MARQUES, Cláudia Lima. Direitos do Consumidor no Mercosul. p. 17.

${ }^{41}$ STIGLITZ, Gabriel. Modificaciones a la Ley Argentina de Defensa Del Consumidor y su influencia en el Mercosur. In: Revista de Direito do Consumidor. São Paulo: Revista dos Tribunais, n. 29, p. 9-20, jan./mar. 1999. p. 18.
} 
AZEVEDO, Antonio Junqueira de. A arbitragem e o Direito do Consumidor. Revista da Faculdade de Direito de São Paulo, São Paulo, n. 91, p. 265-275, jan./dez. 1996.

BAPTISTA, Luiz Olavo. O Mercosul, suas instituições e ordenamento jurídico. São Paulo: LTr, 1998.

BATISTI, Leonir. Direito do consumidor paras o Mercosul: enfoque jurídico e econômico dos blocos de integração. 2. ed. rev. e atual. Curitiba: Juruá, 2003.

BONATTO, Cláudio; MORAES, Paulo Valério Dal Pai. Questões controvertidas no código de defesa do consumidor. 2. ed. Porto Alegre: Livraria do Advogado, 1999.

BRASIL. Decreto 2.181, de 20 de março de 1997. Dispõe sobre a organização do Sistema Nacional de Defesa do Consumidor. Diário Oficial [da] República Federativa do Brasil, Brasília.

. Lei 8.078, de 11 de setembro de 1990. Código de Proteção e Defesa do

Consumidor. Diário Oficial [da] República Federativa do Brasil, Brasília.

BRASIL. Câmara dos Deputados. Comissão de Defesa do Consumidor, Meio Ambiente e Minorias. Sistema nacional de defesa do consumidor: avaliação e perspectivas. Brasília, 2001.

CHRISTINI, Rodrigo Marinho. $\mathbf{O}$ conceito de consumidor e a limitação do seu alcance para as pessoas jurídicas. Disponível em

<http://cristianemarinhoconsumidor.vilabol.uol.com.br/17.html>

D’ANGELIS, Wagner Rocha. Mercosul: da intergovernabilidade à supranacionalidade? Perspectivas jurídicas para a efetivação do mercado comum. Curitiba: Juruá, 2000.

DE LUCCA, Newton. Direito do consumidor. São Paulo: Quartier Latin, 2003.

DORNELES, Renato Moreira. Tutela administrativa dos consumidores no Brasil como paradigma aos países do Mercosul. Curitiba: Juruá, 2003.

DRESIN DE KLOR, Adriana. et. al. Solução de controvérsias: OMC, União Européia e Mercosul. Rio de Janeiro: Fundação Konrad Adenauer, 2004. 
FALLON, Marc. Lê droit des rapports internationaux de consommation. Journal du Droit International, Paris, n. 4, p. 765-847, oct./déc. 1984.

FASQUELLE, Daniel; MEUNIER, Patrick. Le droit communautaire de la consummation: bilan et perspectives. Paris: La documentation Française, 2002.

FELLOUS, Beyla Esther. Proteção do consumidor no Mercosul e na União Européia. São Paulo: Revista dos Tribunais, 2003. (Biblioteca de Direito do Consumidor, v. 24).

FILOMENO, José Geraldo Brito. Manual dos direitos do consumidor. 6. ed. São Paulo: Atlas, 2003.

GRINOVER, Ada Pellegrini. O código de defesa do consumidor no sistema sócioeconômico brasileiro. Revista da Faculdade de Direito de São Paulo, São Paulo, n. 91, p. 277-287, jan./dez. 1996.

. Código de defesa do consumidor comentado pelos autores do anteprojeto. 4. ed. Rio de Janeiro: Forense Universitária, 1995.

Código de defesa do consumidor comentado pelos autores do anteprojeto. 6. ed. Rio de Janeiro: Forense Universitária, 1999.

JACOBINA, Paulo Vasconcelos. A publicidade do direito do consumidor. Rio de Janeiro: Forense, 2002.

JACYNTHO, Patrícia Helena de Ávila; ARNOLDI, Paulo Roberto Colombo. A proteção contratual ao consumidor no Mercosul. Campinas: Interlex, 2001.

JAMIN, Christophe; MAZEAUD, Denis. L'harmonisation du droit des contrats en Europe. Paris: Economica, 2001.

JO, Hee Moon. Introdução ao direito internacional. São Paulo: LTr, 2000.

LEITE, Eduardo de Oliveira. A monografia jurídica. 6. ed. rev., atual. e ampl. São Paulo: Revista dos Tribunais, 2003. (Série métodos em direito, v. 1.)

LEITE, Roberto Basilone. Introdução ao direito do consumidor: os direitos do consumidor e a aplicação do código de defesa do consumidor. São Paulo: LTr, 2002. 
LUIZ, Denise de Souza. Integração jurídico-social do Mercosul. Curitiba: Juruá, 2002.

MARAN, Mara Suely Oliveira e Silva. Publicidade e proteção ao consumidor no âmbito do Mercosul. Curitiba: Juruá, 2003.

MARQUES, Cláudia Lima. A insuficiente proteção do consumidor nas normas de direito internacional privado: da necessidade de uma Convenção Interamericana (CIDIP) sobre a lei aplicável a alguns contratos e relações de consumo. Revista dos Tribunais, São Paulo, n. 788, p. 11-56, jun. 2001.

Contratos no CDC. 2. ed. São Paulo: RT, 1995.

Direitos do Consumidor no Mercosul: algumas sugestões frente ao impasse.

Revista de Direito do Consumidor, São Paulo, n. 31, p. 16-44, jul./set.1999.

. Mercosul como legislador em matéria de Direito do Consumidor: Crítica ao Projeto de Protocolo de Defesa do Consumidor. Revista de Direito do Consumidor, São Paulo, n. 26, p. 53-76, jan./mar. 1998.

MERCOSUL. Acordo interinstitucional de entendimento entre os órgãos de defesa do consumidor dos Estados-partes do Mercosul para a defesa do consumidor visitante. 2004.

Declaração presidencial dos direitos fundamentais dos consumidores do Mercosul. 2000.

. Protocolo de Olivos. 2002.

. Protocolo de Ouro Preto: Protocolo adicional ao tratado de assunção sobre a estrutura institucional do Mercosul. 1994.

Protocolo de Santa Maria sobre jurisdição internacional em matéria de relações de consumo. 1996.

. Tratado de Assunção para a constituição de um mercado comum entre a República Argentina, a República Federativa do Brasil, a República do Paraguai e a República Oriental do Uruguai. 1991. 
PASCUTI, Caroline Paludetto. O Mercosul à luz do seu projeto de Protocolo de Defesa do Consumidor. Curitiba, 51 f. Trabalho de Conclusão de Curso (Graduação)-Centro de Ciências Jurídicas e Sociais da Pontifícia Universidade Católica do Paraná.

PERIN JR, Ecio. A globalização e o Direito do Consumidor: aspectos relevantes sobre a harmonização legislativa dentro dos mercados regionais. Barueri: Manole, 2003.

PIMENTEL, Luiz Otávio. Mercosul no cenário internacional. Curitiba: Juruá, 1998.

RICHTER, Karina. Consumidor e Mercosul. Curitiba: Juruá, 2002.

SOARES, Paulo Brasil Dill. Código de Defesa do Consumidor comentado. 6. ed. Rio de Janeiro: Destaque, 2000.

STIGLITZ, Gabriel. Modificaciones a la ley argentina de defensa del consumidor y su influencia en el Mercosur. Revista de Direito do Consumidor, São Paulo, n. 29, p. 9-20, jan./mar. 1999. 